\title{
Emotional and cognitive consequences of head injury in relation to the Glasgow outcome scale
}

\author{
J T L Wilson, L E L Pettigrew, G M Teasdale
}

\begin{abstract}
Objective-There is current debate over the issue of the best way of assessing outcome after head injury. One criticism of scales of disability and handicap such as the Glasgow outcome scale (GOS) is that they fail to capture the subjective perspective of the person with head injury. The aims of the study were to investigate aspects of the validity of structured interviews for the GOS, and address the issue of the relation between the GOS and subjective reports of health outcome.

Methods-A total of 135 patients with head injury were assessed using the GOS and an extended GOS (GOSE) and other measures of outcome and clinical status at 6 months after injury.

Results-There were robust correlations between the GOS and measures of initial injury severity (particularly posttraumatic amnesia) and outcome assessed by disability scales (particularly the disbility rating scale (DRS)); however, associations with cognitive tests were generally modest. There were also strong correlations with self report measures of health outcome: both the GOS and GOSE were related to depression measured by the Beck depression inventory, mental wellbeing assessed by the general health questionnaire, and to all subscales of the short form-36. The GOS scales were also strongly associated with frequency of reported symptoms and problems on the neurobehavioural functioning inventory. Conclusions-The GOS and GOSE show consistent relations with other outcome measures including subjective reports of health outcome; they thus remain useful overall summary assessments of outcome of head injury.

(F Neurol Neurosurg Psychiatry 2000;69:204-209)
\end{abstract}

Keywords: head injury; outcome; Glasgow outcome scale

The Glasgow outcome scale (GOS) is the most widely used method to describe overall outcome after head injury. ${ }^{1}$ The GOS is quick to administer, can be applied to all cases, and has clinically relevant categories. These practical advantages have led to its widespread adoption in early management studies and clinical trials. We have recently described a standard format for an interview on which to base assessment of GOS category, ${ }^{23}$ which removes ambiguity, ${ }^{4}$ and previous lack of guidelines. ${ }^{5}$ This improves the reliability of the scale, ${ }^{2}$ but it is important to establish the relation between this format of the GOS, particularly the extended GOS (GOSE), and other measures of outcome and clinical status.

Relations have been reported between the GOS and injury severity, ${ }^{6}$ neuropsychological impairment,${ }^{67}$ and measures of disability and handicap..$^{8-11}$ However, in outcome assessment there is an increasing focus on measures of health outcome incorporating the person's own perspective. The extent to which assignments on the GOS may miss important aspects of quality of life has not been studied. ${ }^{8}$

The present study therefore had two aims. Firstly, to investigate aspects of the validity of the structured interviews for the GOS and GOSE through relating their results to indices of injury severity and subsequent limitations. Secondly, to gain greater understanding of the relation between disability and handicap as assessed by the GOS and other measures of outcome, particularly those reflecting subjective perception of health.

\section{Method}

PATIENTS

One hundred and thirty five patients with head injury (113 male patients) who had been admitted to the regional neurosurgical unit were recruited to the study. We excluded patients previously admitted for a neurosurgical or psychiatric disorder, or treatment for alcohol misuse. Informed consent was obtained for all patients. The participants were aged between 16 and 69 (mean (SD) 36.74 (13.92) years). Classified by the worst recorded Glasgow coma score (GCS) ${ }^{12} 48 \quad(36 \%)$ patients had severe injury (GCS $\leqslant 8), 28(21 \%)$ a moderate injury (GCS 9-12), and 59 (44\%) a mild/minor injury (GCS 12-15). Seventy two $(53 \%)$ had undergone a neurosurgical operation.

PROCEDURE

Participants were assessed 5 to 10 months after injury (mean (SD) 7.39 (1.19) months) and interviewed either alone $(65 \%)$ or with a relative or friend $(35 \%)$. The duration of posttraumatic amnesia (PTA) was determined at interview.

Ratings on the GOS and GOSE were obtained by a research psychologist using a structured interview. ${ }^{2}$ The GOS is a five point scale: death, vegetative state, severe disability (SD), moderate disability (MD), and good recovery (GR). The GOSE is an eight point scale in which the last three categories on the GOS are divided into upper and lower bands. The interview to obtain information to apply 
Table 1 Spearman correlations between the GOS and GOSE and demographic, clinical, and outcome variables

\begin{tabular}{|c|c|c|}
\hline & GOS & GOSE \\
\hline \multicolumn{3}{|l|}{ Demographic: } \\
\hline Age at injury & -0.08 & -0.10 \\
\hline Premorbid IQ (NART) & $-0.31^{\star \star}$ & $-0.27^{\star \star}$ \\
\hline \multicolumn{3}{|l|}{ Injury severity: } \\
\hline Length of PTA & $-0.50^{\star \star}$ & $-0.52^{\star \star}$ \\
\hline $\mathrm{A}$ and $\mathrm{E}$ admission GCS & $0.33^{\star \star}$ & $0.32^{\star \star}$ \\
\hline \multicolumn{3}{|l|}{ Disability scales: } \\
\hline Barthel activities of daily living index & $0.47^{\star \star}$ & $0.46^{\star \star}$ \\
\hline Disability rating scale & $-0.89^{\star \star}$ & $-0.89^{\star \star}$ \\
\hline \multicolumn{3}{|l|}{ Cognitive tests: } \\
\hline Rey figure-copy & $0.21^{\star}$ & $0.22^{\star}$ \\
\hline Rey figure-immediate recall & $0.28^{\star \star}$ & $0.29^{\star \star}$ \\
\hline Controlled oral word association & $0.44^{\star \star}$ & $0.42^{\star \star}$ \\
\hline Symbol digit modalities test & $0.32^{\star \star}$ & $0.33^{\star \star}$ \\
\hline Trailmaking part B & $-0.36^{\star \star}$ & $-0.35^{\star \star}$ \\
\hline $\begin{array}{l}\text { Grooved pegboard-non-dominant } \\
\text { hand }\end{array}$ & $-0.38^{\star \star}$ & $-0.34^{\star \star}$ \\
\hline Grooved pegboard-dominant hand & $-0.28^{\star \star}$ & $-0.23^{\star}$ \\
\hline Wisconsin card sort test & $-0.21^{\star}$ & $-0.19^{\star}$ \\
\hline Paired associates - immediate recall & $0.21^{\star}$ & $0.21^{\star}$ \\
\hline Paired associates - delayed recall & $0.32^{\star \star}$ & $0.32^{\star \star}$ \\
\hline Logical memory - immediate recall & $0.39^{\star \star}$ & $0.34^{\star \star}$ \\
\hline Logical memory - delayed recall & $0.42^{\star \star}$ & $0.37^{\star \star}$ \\
\hline \multicolumn{3}{|l|}{ Subjective health outcome: } \\
\hline Beck depression inventory & $-0.61^{\star \star}$ & $-0.64^{\star \star}$ \\
\hline General health questionnaire & $-0.57^{\star \star}$ & $-0.59^{\star \star}$ \\
\hline \multicolumn{3}{|l|}{ SF-36: } \\
\hline Physical functioning & $0.55^{\star \star}$ & $0.56^{\star \star}$ \\
\hline Role-physical & $0.61^{\star \star}$ & $0.62^{\star \star}$ \\
\hline Pain & $0.49^{\star \star}$ & $0.50^{\star \star}$ \\
\hline General health & $0.58^{\star \star}$ & $0.59^{\star \star}$ \\
\hline Social functioning & $0.67^{\star \star}$ & $0.71^{\star \star}$ \\
\hline Role-emotional & $0.55^{\star \star}$ & $0.57^{\star \star}$ \\
\hline Energy and fatigue & $0.41^{\star \star}$ & $0.47^{\star \star}$ \\
\hline Mental health & $0.54^{\star \star}$ & $0.56^{\star \star}$ \\
\hline \multirow{2}{*}{\multicolumn{3}{|c|}{$\begin{array}{l}\text { Head injury symptoms and problems: } \\
\text { NFI - patient }\end{array}$}} \\
\hline & & \\
\hline Depression & $-0.57^{\star \star}$ & $-0.63^{\star \star}$ \\
\hline Aggression & $-0.35^{\star \star}$ & $-0.37^{\star \star}$ \\
\hline Somatic & $-0.33^{\star \star}$ & $-0.38^{\star \star}$ \\
\hline Motor & $-0.58^{\star \star}$ & $-0.58^{\star \star}$ \\
\hline Memory/attention & $-0.55^{\star \star}$ & $-0.58^{\star \star}$ \\
\hline Communication & $-0.43^{\star \star}$ & $-0.44^{\star \star}$ \\
\hline \multicolumn{3}{|l|}{ NFI - Relative or friend: } \\
\hline Depression & $-0.65^{\star \star}$ & $-0.66^{\star \star}$ \\
\hline Aggression & $-0.48^{\star \star}$ & $-0.47^{\star \star}$ \\
\hline Somatic & $-0.47^{\star \star}$ & $-0.51^{\star \star}$ \\
\hline Motor & $-0.68^{\star \star}$ & $-0.69^{\star \star}$ \\
\hline Memory/attention & $-0.66^{\star \star}$ & $-0.69^{\star \star}$ \\
\hline Communication & $-0.61^{\star \star}$ & $-0.64^{\star \star}$ \\
\hline
\end{tabular}

${ }^{\star} \mathrm{p}<0.05 ;{ }^{\star \star} \mathrm{p}<0.01$.

Table 2 Duration of post-traumatic amnesia (PTA) and the GOSE

\begin{tabular}{llllll}
\hline \multirow{5}{*}{ GOSE } & \multicolumn{2}{l}{ Length of PTA } & & \\
\cline { 2 - 5 } & $<1 h$ & $1-24 h$ & $1-7$ days & $>7$ days & Total \\
\hline GR upper & 6 & 6 & 3 & 3 & 18 \\
GR lower & 4 & 6 & 16 & 8 & 34 \\
MD upper & 2 & 1 & 11 & 10 & 24 \\
MD lower & 1 & 2 & 6 & 11 & 20 \\
SD upper & & & 4 & 9 & 13 \\
SD lower & & & 6 & 20 & 26 \\
Total & 13 & 15 & 46 & 61 & 135 \\
\hline
\end{tabular}

the GOSE consists of a series of questions covering consciousness, independence inside and outside the home, major social roles (work, social and leisure activities, family and friendships), and return to normal life. The final rating is based on the lowest category of outcome indicated by the responses. For the purposes of this study we did not attempt to distinguish disability due to brain injury from disability due to extracranial injuries occurring at the same time as the head injury. Categories of GOS were obtained by collapsing the subdivisions of the GOSE. Of the 135 participants 39 $(29 \%)$ were rated as severely disabled, 44

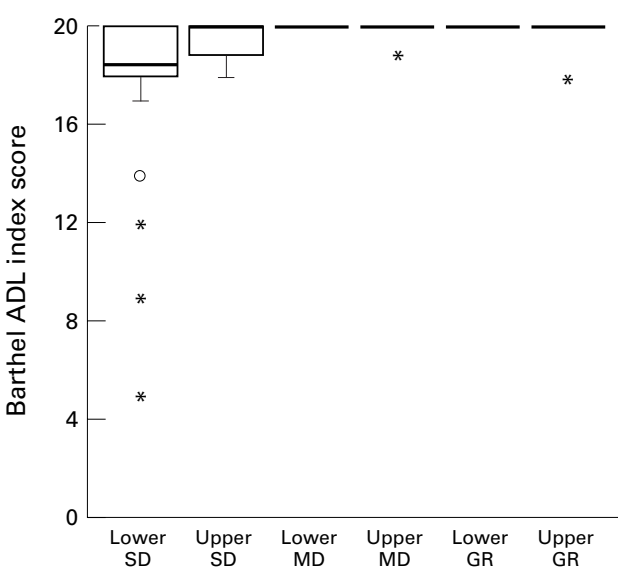

Figure 1 Box plot of Barthel ADL index scores against category on the GOSE. The box represents the interquartile range which contains $50 \%$ of values on the Barthel index in each GOSE category; the median is indicated by a heavy line. The whiskers are lines that extend from the box to the highest and lowest values, excluding outliers. Outliers (o) are cases with values between 1.5 and 3 box lengths from the upper or lower edge of the box. Extremes $\left({ }^{\star}\right)$ are cases with values more than three box lengths from the upper or lower edge of the box.

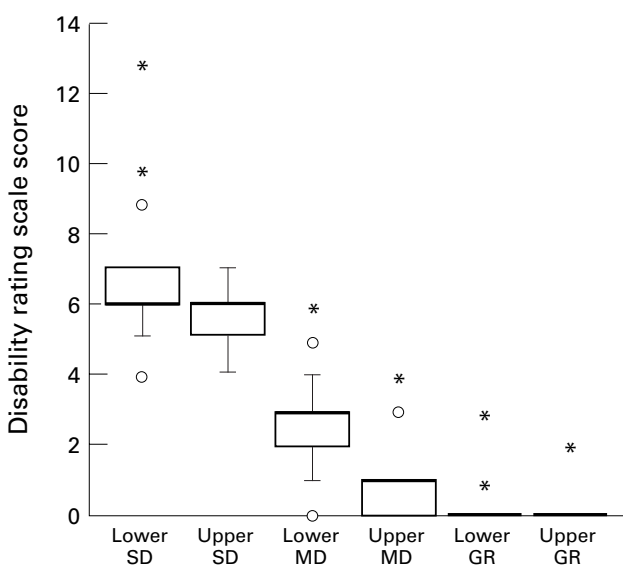

Figure 2 Box plot of disability rating scale scores against category on the GOSE.

(33\%) as moderately disabled, and $52(39 \%)$ as good recovery.

Disability scales

The disability rating scale (DRS) ${ }^{13}$ and the Barthel activities of daily living (ADL) index ${ }^{14}$ were completed by the interviewer at the time of follow up.

Neuropsychological tests

The tests administered were selected from the portfolio described by a working party of the National Institute of Neurological Disorders and Stroke. ${ }^{15}$ The tests were the Rey figure copy and delayed recall; grooved pegboard with left and right hands; controlled oral word association test (COWAT); symbol digit modalities test; trail making form B; and Wisconsin card sort test. In addition, verbal memory ability was assessed using immediate and delayed paired associates learning and immediate and delayed logical memory. ${ }^{16}$ We also employed the national adult reading testrevised (NART) as an estimate of before injury. ${ }^{17}$ 


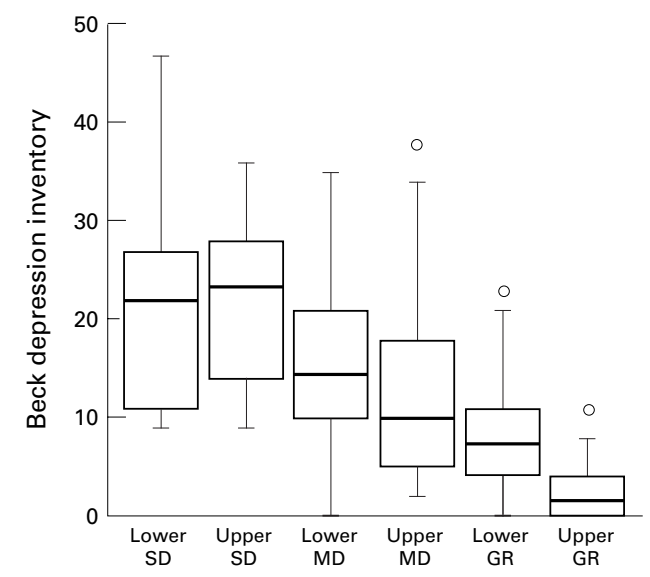

Figure 3 Box plot of Beck depression inventory scores against category on the GOSE.

\section{Health outcome}

The United Kingdom version of the 36-item short form health survey $(\mathrm{SF}-36)^{18}(\mathrm{n}=135)$, the general health questionnaire ${ }^{19} \quad(n=109)$, and the Beck depression inventory ${ }^{20}(n=109)$ were administered. The purpose of each questionnaire was explained to the patient with head injury, and all patients indicated that they comprehended the task involved.

Head injury symptoms and problems

The neurobehavioural functioning inventory $(\mathrm{NFI})^{21}$ was completed independently by the patient with head injury $(n=106)$ and also by a relative or close friend $(n=100)$. The frequency of occurrence for each item on the NFI was rated on a four point scale: never (1), sometimes (2), often (3), or always (4).

\section{Results}

The main relations are summarised first, and then their nature is described in more detail in subsequent sections. Table 1 shows Spearman correlations between the GOS and GOSE ratings and the main variables and measures studied. There are substantial correlations between the GOS and GOSE ratings and measures of both initial injury severity (particularly PTA) and of sequelae of injury assessed by disability scales (particularly the DRS). Relations with cognitive tests are generally more modest, and strongest for controlled oral word association and delayed logical memory. There are strong correlations with self report measures of emotional state and quality of life; thus, the GOS and GOSE ratings were related to the extent of depression measured by the Beck depression inventory, and to each subscale of the SF-36. The GOS and GOSE ratings were also related to all subscales of the NFI, with strongest correlations with the reports provided by relatives or friends.

\section{DEMOGRAPHIC VARIABLES}

There was no significant effect of age on quality of outcome in these survivors of head injury. Preinjury IQ estimated by the NART had modest but significant relations with the GOS and GOSE ratings.

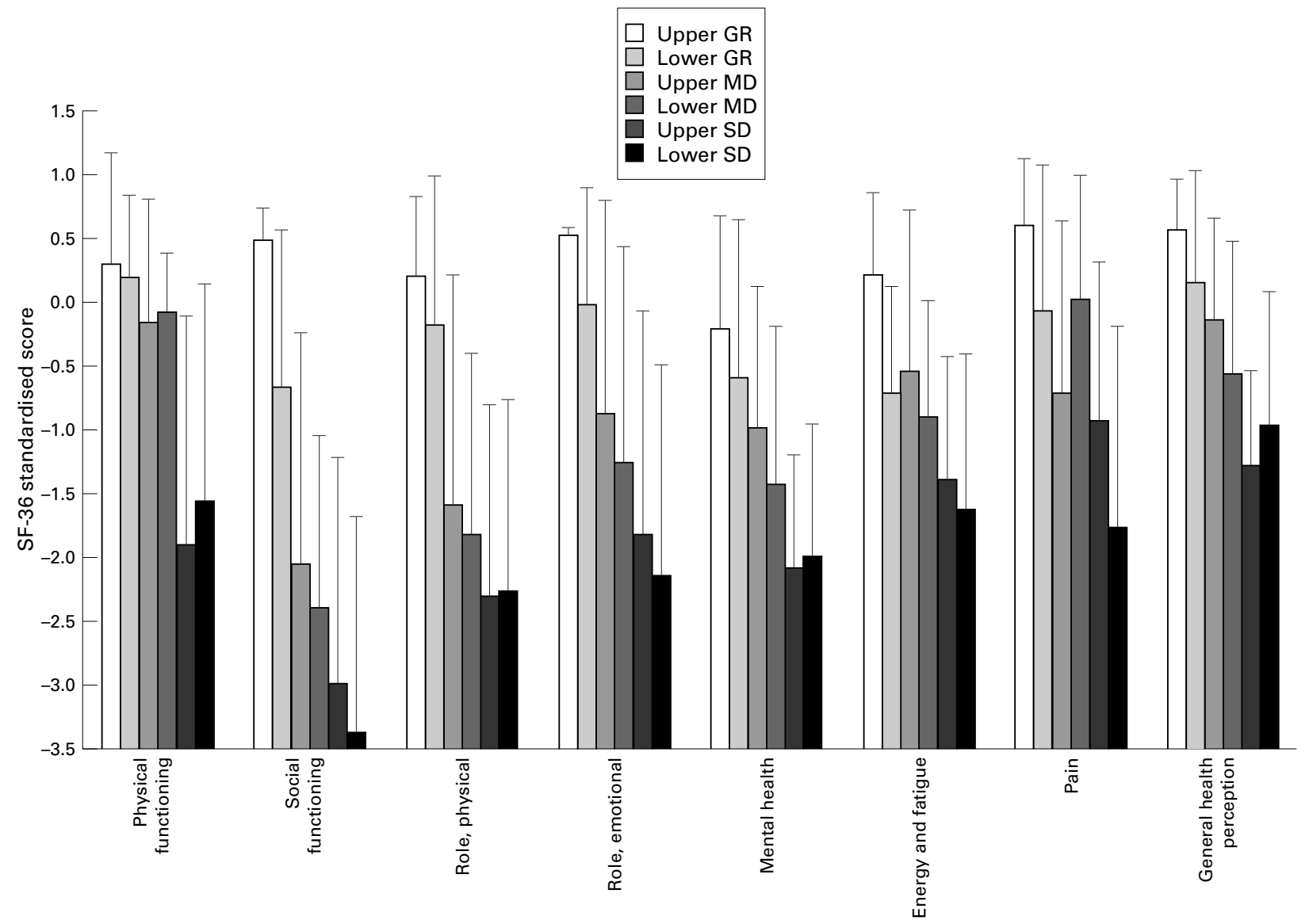

Figure 4 SF-36: mean subscale scores of groups in each category of the GOSE. Error bars represent $1 S D$. 


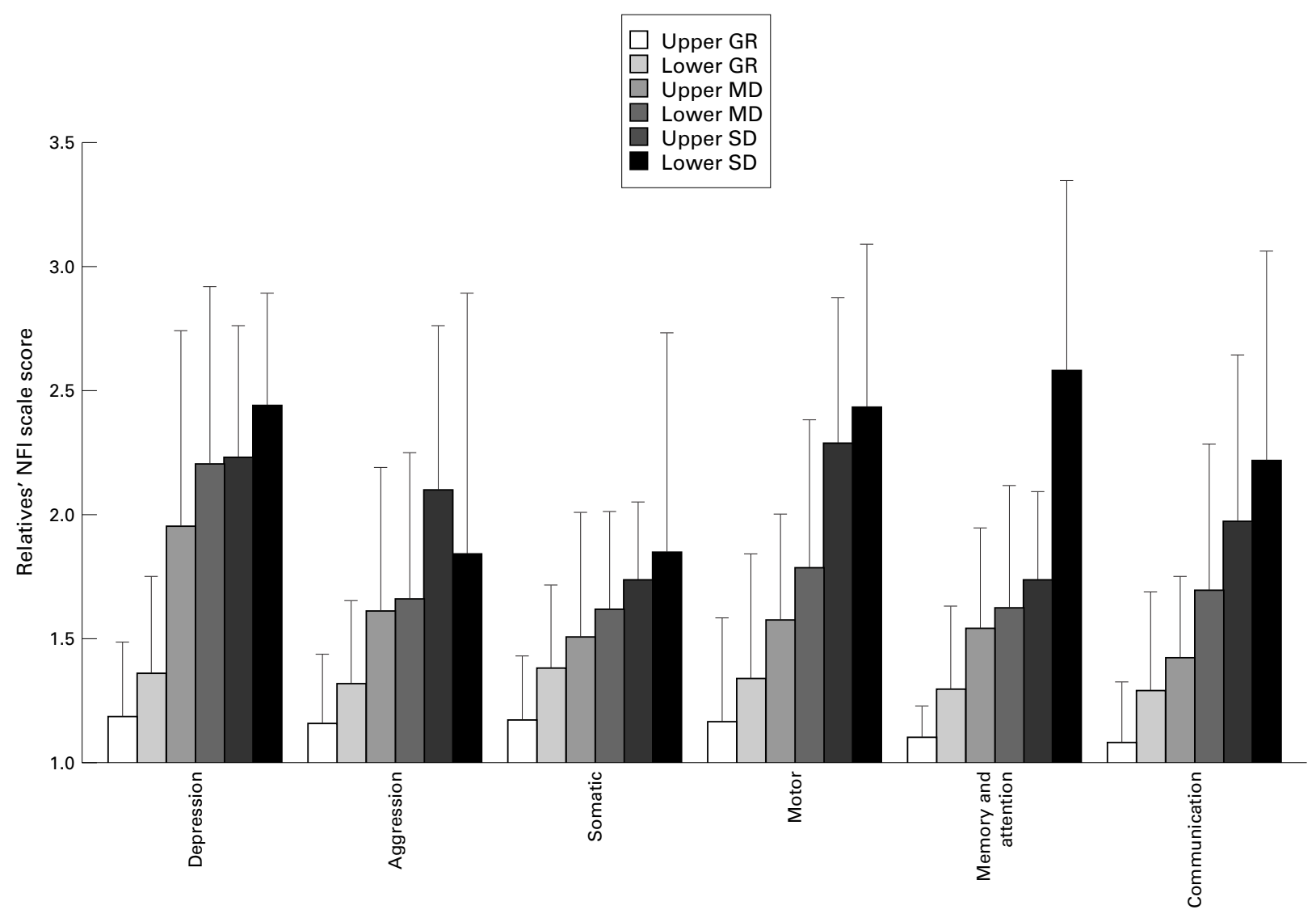

Figure 5 Relatives'NFI: mean subscale scores of groups in each category of the GOSE. The minimum NFI score is 1 and the maximum is 4. Error bars represent $1 S D$.

MEASURES OF INJURY SEVERITY

There was a stronger correlation between PTA and outcome than between GCS and outcome. Cross tabulation of GOSE with duration of PTA (table 2) indicated that the relation held across the full range of outcomes. In the lower category of GR $71 \%$ of participants had a PTA of greater than 1 day compared with only $33 \%$ of participants in the upper category of GR. This is consistent with the sequelae experienced by participants in the lower GR group being at least in part a reflection of more severe brain injury than in the upper GR group. Furthermore the proportion of patients with PTA greater than 7 days was highest $(77 \%)$ in the lower category of SD, consistent with this group having had the most severe injuries.

\section{DISABILITY SCALES}

Scores on the Barthel index of daily living correlated significantly with GOS and GOSE ratings, but showed a very substantial ceiling effect (fig 1). Thus, $85 \%$ of participants were assigned a maximum score on the Barthel index. Although the categories of the Barthel index discriminate between upper and lower categories of severe disability the ceiling effect was already apparent in the upper category of SD. The Barthel index reflects competence in activities of daily living within the home, and does not assess abilities necessary for independence outside the home. There was a strong correlation between allocation on the DRS and on the GOS. The relation is illustrated in fig 2, which shows also that there is a ceiling effect on the DRS in the upper moderate disability range. The DRS apparently does not discriminate effectively between the top three categories in the GOSE, to which $56 \%$ of participants in the current sample were allocated.

\section{COGNITIVE TESTS}

There were significant correlations between the GOS scales and eight of the 12 neuropsychological tests (table 1). To determine if significant relations were due to differences in premorbid IQ, partial correlation coefficients were computed controlling for NART. There were significant $(p<0.05)$ correlations between the GOS in original and extended forms and the results obtained from the COWAT, symbol digit modalities test, grooved pegboard dominant and non-dominant hands, logical memory immediate and delayed; and between the GOSE and paired associates delayed recall. Thus associations between outcome classified by the GOS and the results of cognitive tests do not simply reflect preinjury IQ.

SUBJECTIVE PERCEPTION OF HEALTH OUTCOME The relation between assignments on the GOSE and the score obtained using the Beck depression inventory is shown in figure 3. On the GOSE scale, the median values of the Beck scores for the groups are appropriately ordered, apart from the scores reported from the most severely disabled group. This reflects a wide range of values in the lower category of SD, 


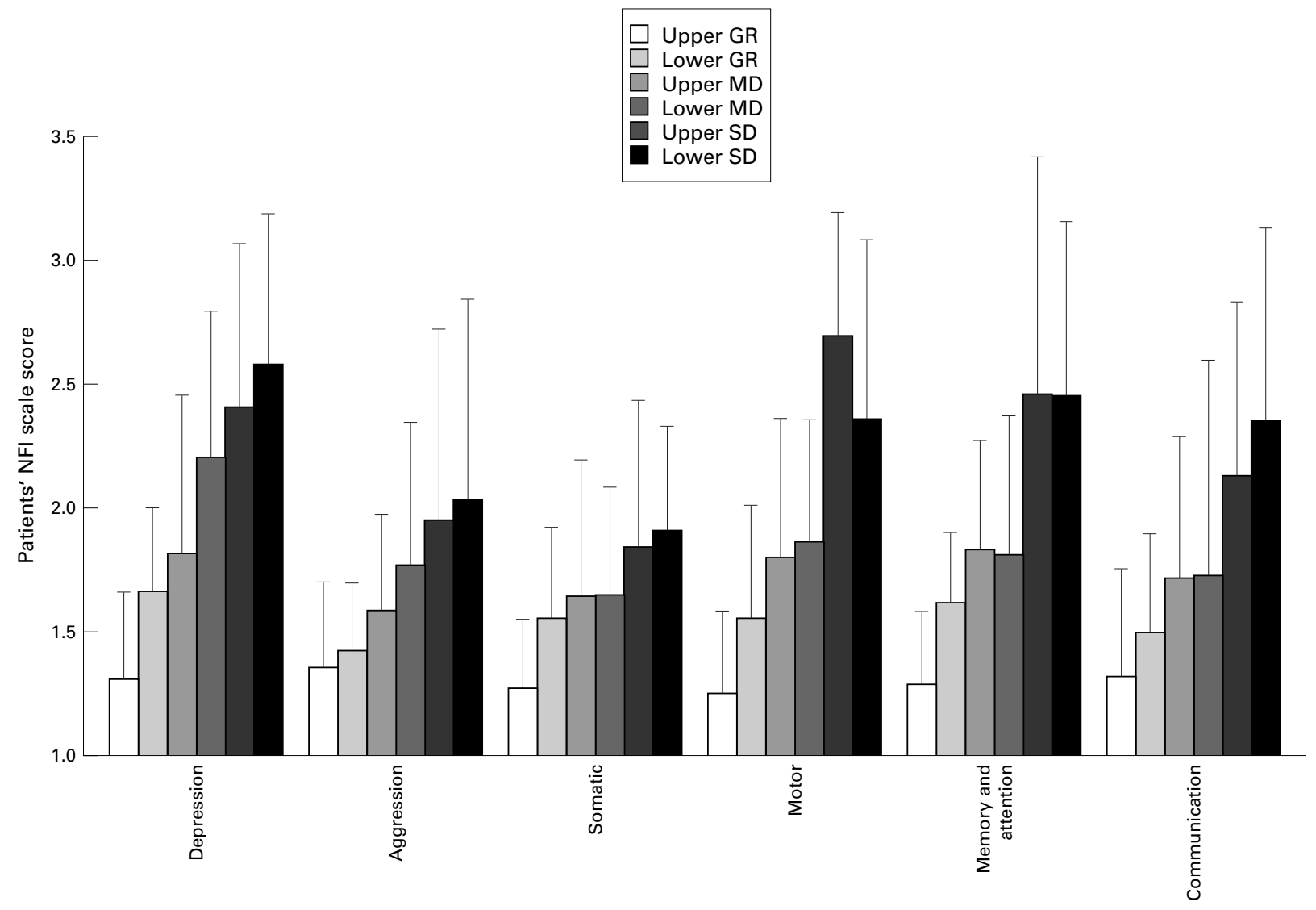

Figure 6 Head injured participants' NFI: mean subscale scores of groups in each category of the GOSE. Error bars represent 1 SD.

which contained those reporting the highest levels of depressive symptomatology, but also contained patients reporting relatively little affective disturbance.

The allocation on the GOS correlated significantly with scores on the general health questionnaire, and with results for each subscale of the SF-36. Standardised scores for the SF-36 were calculated using the norms provided by Jekinson et al. ${ }^{18}$ Mean scores of groups in each category of the GOSE for each subscale are illustrated in fig 4 . The mean scores of the groups are generally appropriately ordered for each subscale; there was a particularly strong relation between the rating on the GOSE and social functioning.

HEAD INJURY SYMPTOMS AND PROBLEMS

Items in the NFI were grouped into six subscales and mean ratings were calculated. The relation between the GOSE category and the relatives' NFI score is shown in fig 5, and the patients' NFI in fig 6 . The figures illustrate consistent associations between NFI subscale scores and the GOSE ratings, particularly for the NFI scores based on reports from relatives or friends. Comparison of figs 5 and 6 indicates that the overall frequency of reports of problems by patients and relatives was similar.

\section{Discussion}

The results of this study show good concordance between the GOS scales and injury severity, rating of disability, the results of cognitive testing, measures of the perception of health, and symptoms reported by people with head injury and their relatives. The findings thus strongly support the validity of assigning the GOS using the structured interview, ${ }^{2}$ both for the original five category scale and for eight categories in the GOSE. The structured interview specifies criteria for subdividing upper and lower bands of the top three outcome categories, rather than simply depending on the judgement of the rater as originally proposed. ${ }^{22}$ We focused on outcome at 6 months, which is often chosen as a follow up period for assessing outcome in studies of patients with head injury. ${ }^{22}$ At this stage after injury the severity of the initial injury is still quite closely related to the extent of sequelae. However, adaptation and adjustment continue beyond 6 months, and this may change the relations between the GOS and cognitive impairment ${ }^{7}$ and emotional state. $^{23}$

The DRS score also showed a strong correlation with the GOS rating, but the results confirm that DRS grades show a ceiling effect when compared with the GOS. ${ }^{11}$ The results support the view that the DRS may be of value in monitoring the progress of severely disabled patients, ${ }^{10}$ but is of less value in rating higher levels of outcome. Similarly, the results show that the Barthel index may be of use in subdividing the severely disabled group but it is of no value in discriminating the status of most survivors of head injury.

The current findings are in accord with previous studies of the relation between outcome categories on the GOS and evidence of neuro- 
psychological impairment that suggested a significant but modest relation. ${ }^{6724}$ The finding that cognitive impairment is not more strongly related to social disability after head injury is in line with several recent reports that cognitive status does not have a major influence on disability and handicap..$^{25}$

The comparisons with the results from the Beck, SF-36, and general health questionnaires showed good general agreement between these subjective measures of health outcome and the GOS and GOSE. Previous work has shown a strong association between the GOS and affective state 6 months after injury. ${ }^{23}$ The results show particularly pronounced separation of GOSE categories on the social functioning subscale of the SF-36. This strongly supports the view that the GOS does not simply reflect physical disability but also encompasses social limitations after head injury. The GOS thus successfully captures aspects of outcome which are significant for emotional adjustment and quality of life.

Boake and $\mathrm{High}^{8}$ report examples of cases illustrating a dissociation between disability and quality of life after head injury. A severely disabled person may be supported financially and become adjusted emotionally to loss of independence; on the other hand, a moderately disabled person may find themselves in poor circumstances and be much more distressed. These cases raise the issue of whether support for severely disabled patients typically leads to better emotional adjustment in these patients than moderately disabled patients. This is not supported by findings for our sample of patients, although there may be individual exceptions The findings also contradict the common belief that patients with head injury often lack insight into their difficulties. If so, then there should be little or no relation between emotional state and the extent of disability. By contrast, we found that the overwhelming trend is for greater disability and handicap to be associated with poorer subjective outcome. Only in the lower severely disabled category was it possible that a substantial proportion of our patients may have shown loss of insight or paradoxical euphoria.

Appropriate use of the GOS depends on having a clear conception of the strengths and limitations of the scale. The GOS provides an overall measure of social changes due to head injury, and does not provide a detailed assessment of impairment and disability. Simplification is achieved by using a core set of roles to describe major aspects of people's lifestyles, including ability to manage their own affairs, employment, social and leisure activities, and close relationships. These roles are readily understood by the patient and, in conscious survivors, changes in these roles are used to assess the impact of impairment and disability caused by head injury. It should be borne in mind that the GOS is primarily intended to describe outcome in groups of cases, and is not of value, for example, in the individual assessment necessary for rehabilitation or treatment of specific problems related to head injury. The current comparison between GOS and GOSE ratings and other measures supports the validity of the scales. The results also support the appropriateness of the GOS as an overall summary measure of outcome after head injury. The assessment is relevant to differentiating the sequelae of different injuries, and provides a link between the specific sequelae and effects on wellbeing and lifestyle.

The study was supported by a project grant from the Chief Scientist Office, Scottish Home and Health Department.

1 Jennett B, Bond $\mathrm{M}$. Assessment of outcome after severe brain damage. A practical scale. Lancet 1975;i:480-4.

2 Wilson JTL, Pettigrew LEL, Teasdale GM. Structured interviews for the Glasgow outcome scale and extended Glasgow outcome scale: guidelines for their use. $\mathcal{f}$ Neurotrauma 1998;15:573-85.

3 Teasdale G, Pettigrew L, Wilson JTL, et al. Analyzing outcome of treatment of severe head injury: a review and update on advancing the use of the Glasgow outcome scale. f Neurotrauma 1998;8:587-97.

4 Grant I, Alves W. Psychiatric and psychosocial disturbances in head injury. In: Levin HS, Grafman J, Eisenberg HM, eds. Neurobehavioral recovery from head injury. Oxford: Oxford University Press, 1987:57-72.

5 Anderson SI, Housley AM, Jones PA, et al. Glasgow outcome scale: an inter-rater reliability study. Brain Inj 1993;7:309-17.

6 Levin HS, Grossman RG, Rose JE, et al. Long-term neuropsychological outcome of closed head injury. 7 Neurosurg 1979;50:412-22.

7 Brooks DN, Hosie J, Bond MR, et al. Cognitive sequelae of severe head injury in relation to the Glasgow outcome scale. F Neurol Neurosurg Psychiatry 1986;49:549-53.

8 Boake C, High WM. Functional outcome from traumatic brain injury: unidimensional or multidimensional? $A m \mathcal{F}$ brain injury: unidimensional or m.t.

9 Gouvier WD, Blanton PD, Kittle KS. Reliability and validity of the expanded Glasgow outcome scale and the StoverZieger scale. International fournal of Clinical Neuropsychology $1986 ; 8: 1-2$

10 Hall K, Cope DN, Rappaport M. Glasgow outcome scale and disability rating scale: comparative usefulness in following recovery in traumatic head injury. Arch Phys Med Rehabil 1985;66:35-7.

11 Pettigrew LEL, Wilson JTL, Teasdale GM. Assessing disability after head injury: the improved use of the Glasgow outcome scale. F Neurosurg 1998;89:939-43.

12 Teasdale G, Jennett B. Assessment of coma and impaired consciousness: a practical scale. Lancet 1974; ;i:81-4.

13 Rappaport M, Hall KM, Hopkins K, et al. Disability rating scale for severe head trauma: coma to community. Arch Phys Med Rehabil 1982;63:118-23.

14 Collin C, Wade DT, Davies S, et al. The Barthel ADL index: a reliability study. International Disability Studies 1988;10: $61-3$.

15 Clifton GL, Hayes RL, Levin HS, et al. Outcome measures for clinical trials involving traumatically brain-injured patients: report of a conference. Neurosurgery 1992;31:9758.

16 Wechsler D. The Wechsler memory scale: revised. San Antonio: Psychological Corporation, 1987.

7 Nelson HE, Willison JR. National adult reading test (NART), 2nd ed: test manual. Windsor: NFER-Nelson, 1991.

18 Jenkinson C, Layte R, Wright L, et al. The UK SF-36: an analysis and interpretation manual. Oxford: Health Services Research Unit, University of Oxford, 1996.

19 Goldberg D, Williams P. A user's guide to the general health questionnaire. Windsor: NFER-Nelson, 1988.

20 Beck AT, Steer RA. Beck depression inventory: manual. San Antonio: Psychological Corporation, 1987.

21 Kreutzer JS, Marwitz JH, Seel R, et al. Validation of a neurobehavioral functioning inventory for adults with traumatic brain injury. Arch Phys Med Rehabil 1996;77:116-24.

22 Jennett B, Snoek J, Bond MR, et al. Disability after severe head injury: observations on the use of the Glasgow outcome scale. F Neurol Neurosurg Psychiatry 1981;44:28593.

23 McCleary C, Satz P, Forney D, et al. Depression after traumatic brain injury as a function of Glasgow outcome score. f Clin Exp Neuropsychol 1998;20:270-9.

24 Satz P, Zaucha K, Forney DL, et al. Neuropsychological, psychosocial and vocational correlates of the Glasgow outcome scale at 6 months post-injury: a study of moderate to severe traumatic brain injury patients. Brain Inj 1998;12: 555-67.

25 Smith-Knapp K, Corrigan JD, Arnett JA. Predicting functional independence from neuropsychological tests following traumatic brain injury. Brain Inj 1996;10:651-61.

26 Girard D, Brown J, Burnettstolnack M, et al. The relationship of neuropsychological status and productive outcomes
following traumatic brain injury. Brain Inj 1996;10:663-76. 